\title{
IronIC Patch: A Wearable Device for the Remote Powering and Connectivity of Implantable Systems
}

\author{
Jacopo Olivo, Sandro Carrara, and Giovanni De Micheli \\ Integrated Systems Laboratory - EPFL \\ Lausanne, Switzerland \\ email: jacopo.olivo@epfl.ch
}

\begin{abstract}
A wearable device to power implanted sensors by means of an inductive link is presented. The system, having size $69 \times 40 \mathrm{~mm}^{2}$, is designed to be embedded into a skin patch and located over the implantation area. The system can transfer up to $15 \mathrm{~mW}$ within $6 \mathrm{~mm}$ in air. Tested with a $17 \mathrm{~mm}$ thick beef sirloin placed between the inductors, the device is able to deliver up to $1.17 \mathrm{~mW}$. Downlink communication with the implanted sensors is performed at $100 \mathrm{kbps}$ by using amplitude modulation. Uplink communication is performed at $66.6 \mathrm{kbps}$ by using load modulation. Long range communication between the system and remote devices is enabled by a bluetooth module. The system is powered by two rechargeable lithium-ion polymer batteries and has an autonomy of $10 \mathrm{~h}$ in stand-by mode and about $1.5 \mathrm{~h}$ in transmitting mode.

Index Terms - Inductive link, remote powering, wearable de-
\end{abstract} vice, energy harvesting, implantable sensors.

\section{INTRODUCTION}

Implantable sensors for biomedical applications have been appealing to industry and academia for the past two decades. Possible applications for these devices are the continuous monitoring of the patient and the possibility to achieve personalized therapies [1]. Beyond the sensing aspects, related to the electrochemistry domain, these devices must be minimally invasive to not cause discomfort. Batteries are usually a bottleneck in the miniaturization process. Moreover, their substitution could require the surgery.

Energy harvesting techniques exploit natural or artificial power sources surrounding the person to provide energy to implanted batteries [2,3]. Thus, batteries can be smaller and with a longer lifetime. Remote powering through inductive links is one of the most promising techniques. In such a technique, an alternate current flows into an external inductor; the variable magnetic field generated induces an alternate current into one or more implanted inductors.

A noticeable advantage of this approach is the possibility to enable bidirectional data communication without using an implanted RF transmitter. Data can be sent from the external transmitter to the implanted device (downlink communication) by modulating the amplitude of the power carrier. Alternatively, data can be sent from the implanted device to the

The research work presented was funded by the i-IronIC project and by the NanoSys project. The NanoSys project is within the program ERC-2009-AdG246810 , the i-IronIC project was financed with a grant from the Swiss NanoTera.ch initiative and evaluated by the Swiss National Science Foundation.

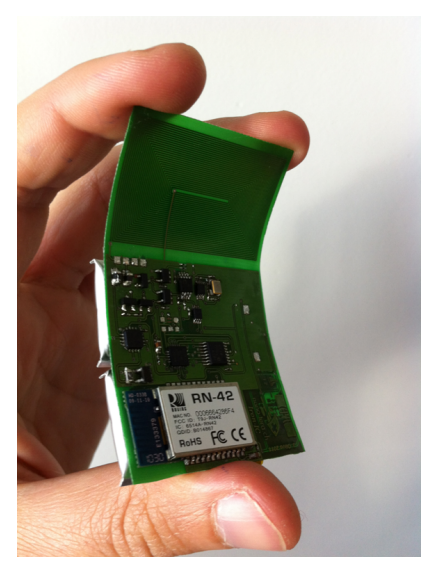

Fig. 1. Photo of the IronIC Patch. The system can be placed over the implantation area to power implanted sensors and communicate with them.

external transmitter (uplink communication) by modulating the internal load. This modulation is detected by the external transmitter as a variation of the current flowing on the transmitting coil due to the different load (backscattering).

A wearable device to transmit power to an implantable sensor is presented in this paper. The system, named IronIC Patch, is shown in Fig. 1. The system is realized on a flexible FR4 substrate to be embedded into a skin patch and located directly over the implantation area. This placement reduces the probability of misalignments between the transmitting and receiving inductors.

The device can transmit power wirelessly to the implanted sensors by driving the transmitting coil with a class-E power amplifier. Downlink communication is achieved by means of an Amplitude Shift Keying (ASK) modulator. Uplink communication is achieved by monitoring the current drawn by the amplifier. The system enables long-range communication with remote devices by means of an embedded bluetooth module. Finally, the device is powered by two rechargeable lithiumions polymer batteries (LiPo).

The system is particularly suitable to power implantable sensors dedicated to glucose and lactate monitoring $[4,5]$. These sensors are usually placed in the subcutaneous zones, quite close to the transmitting inductor. However, the device can be also used in different applications involving a higher distance between transmitter and receiver. 


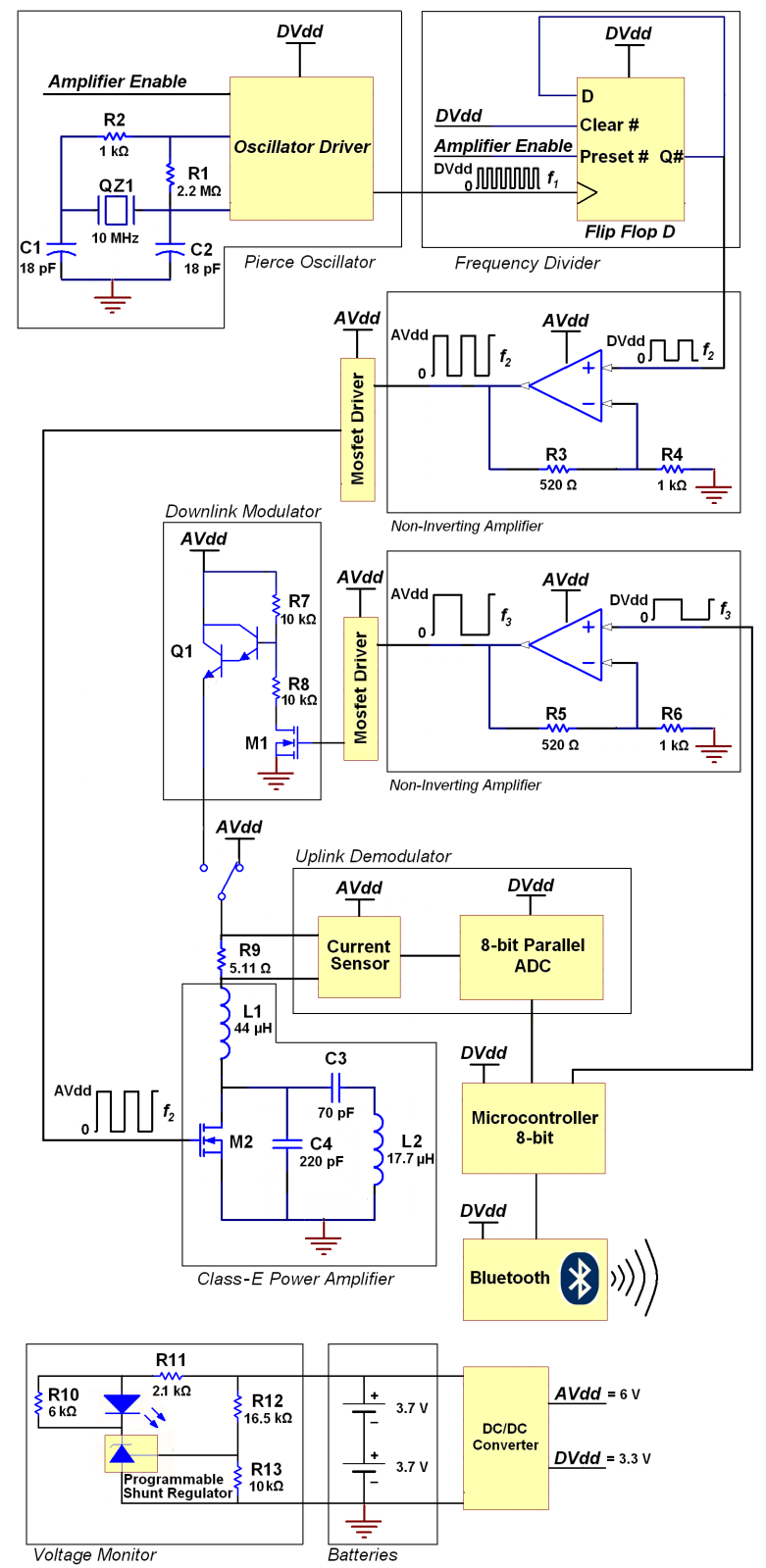

Fig. 2. Schematic of the IronIC Patch at the component-level.

The remainder of the paper is organized as follows. In Section 2, the different components comprising the system are described. In Section 3, the performance of the system is analyzed. Moreover, the system is compared to similar devices presented in the literature. Finally, Section 4 concludes the paper.

\section{SySTEM DESIGN}

In this section, the system is described in detail at the component-level. The different circuit blocks are successively presented in the following subsections.

\section{A. Class-E Power Amplifier}

Amplifiers in class-E, such as the one depicted in Fig. 2, are commonly used to drive inductive links, due to the high efficiency, theoretically equal to $100 \%$ [6-8]. The MOSFET $\mathrm{M}_{2}$, driven by a square waveform, acts as a switch. By properly tuning the capacitors $\mathrm{C}_{3}$ and $\mathrm{C}_{4}$, the current and the voltage across the switch are never different from zero at the same time. Therefore, theoretically the switch does not dissipate power. Choke inductor $\mathrm{L}_{1}$, is used to decouple AC signals of the amplifier from DC supply. Inductor $\mathrm{L}_{2}$ is the transmitting coil.

In this design, the amplifier is driven by a $5 \mathrm{MHz}$ square waveform having $50 \%$ duty cycle. The circuit used to generate that waveform is also shown in Fig. 2. The amplifier can be enabled or disabled by a remote user by acting on the microcontroller through the bluetooth connection.

\section{B. Downlink Modulator}

Downlink communication is achieved by modulating the amplitude of the current flowing on the transmitting inductor $\mathrm{L}_{2}$. To this end, the supply of the amplifier is switched to the downlink modulator (Fig. 2). This last circuit modulates the supply of the amplifier, thus modulating the current on the transmitting inductor. This modulation is detected by an analog demodulator embedded into the implanted sensor. The modulating signal is a bit-stream generated by the microcontroller, which is controlled by the remote user through the bluetooth connection. The bit-rate is set to $100 \mathrm{kbps}$. The modulation depth is determined by the ratio between resistors $R_{7}$ and $R_{8}$.

\section{Uplink Demodulator}

Uplink communication is achieved by varying the load of the internal sensor seen by the transmitter. The load modulation affects not only the current flowing on the external inductor, but also the DC current drawn by the amplifier from the supply and passing through resistor $R_{9}$ (Fig. 2). To demodulate an uplink bitstream, the voltage drop across resistor $R_{9}$ is digitized and analyzed by the microcontroller. A high voltage drop, due to a high current, corresponds to an internal load not short-circuited (digital value 0); alternatively, a low voltage drop, due to a low current, corresponds to a short-circuited internal load (digital value 1).

Since the current drawn by the amplifier depends on several factors, such as the distance between the inductors and the interleaved tissues, the threshold between high and low current is updated prior to each communication. The uplink bitrate is set to $66.6 \mathrm{kbps}$. This bit-rate is slightly lower than the downlink bit-rate due to the computational time required to perform a real-time threshold check. Data acquired from uplink communication are sent to the remote user by means of the bluetooth connection.

\section{Inductor Design}

The external inductor is a 30-turns, planar spiral coil with an area of $38 \times 24 \mathrm{~mm}^{2}$. The copper thickness is $38 \mu \mathrm{m}$, while 


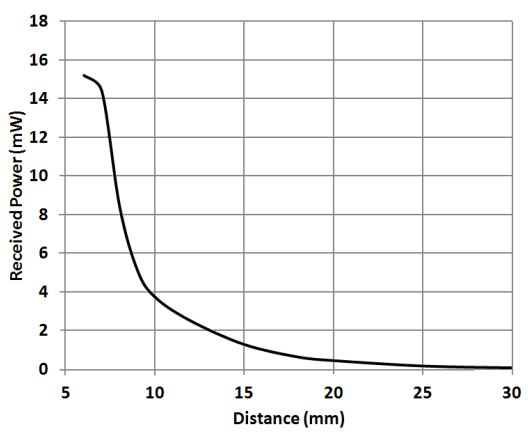

Fig. 3. Transferred power versus distance between inductors in ambient air.

the distance between adjacent turns is $150 \mu \mathrm{m}$. The width of the copper traces is $250 \mu \mathrm{m}$.

The geometry of the external inductor strongly influences the efficiency of the link [9]. The geometry used is a good tradeoff between link efficiency (ratio between the power dissipated on the load and the total power dissipated) and voltage gain (ratio between the voltage supplied to the load and the voltage source). By using as receiving inductor an 8-layers, 14-turns coil with a total volume of $38 \times 2 \times 0.544 \mathrm{~mm}^{3}$, at $5 \mathrm{MHz}$ the link efficiency is about $20 \%$ and the voltage gain is 0.014 . This link efficiency does not include the losses due to the amplifier. In the following section, the power consumption of the amplifier is obtained and the link efficiency is calculated including the losses.

\section{E. Power Supply}

The device is powered by two rechargeable lithium-ion polymer batteries (LiPo). Each battery has a nominal voltage of $3.7 \mathrm{~V}$ and weights $3.7 \mathrm{~g}$. The volume of the single battery is $30.6 \times 20.2 \times 3.6 \mathrm{~mm}^{3}$. Each battery has a capacity of $120 \mathrm{mAh}$ and a maximum discharging rate of $3 \mathrm{~A}$. The maximum charging current is $0.6 \mathrm{~A}$.

The two batteries are placed in series to obtain an overall voltage of $7.4 \mathrm{~V}$ (Fig. 2). Different supply voltages are generated on-board. The analog voltage AVdd is set equal to $6 \mathrm{~V}$. The digital voltage DVdd is set equal to $3.3 \mathrm{~V}$.

A voltage monitor is used to check the batteries and prevent over-discharge. The LED is on when the voltage of the batteries is higher than $6.7 \mathrm{~V}$ and switches off when it is lower.

\section{EXPERIMENTAL RESULTS}

In this section, the performance of the system is evaluated in terms of transferred power and battery consumption. Moreover, the system is compared to similar devices.

\section{A. Performance Evaluation}

The proposed system is realized on an FR4 flexible substrate, having thickness $0.1 \mathrm{~mm}$. The area of the system is $69 \times 40 \mathrm{~mm}^{2}$. The system is tested by using an 8-layers, 14 turns receiving inductor, having volume $38 \times 2 \times 0.544 \mathrm{~mm}^{3}$. Measurements are performed in ambient air.

In this design, capacitors $\mathrm{C}_{3}$ and $\mathrm{C}_{4}$ are chosen to provide a transmitted power higher than $10 \mathrm{~mW}$. This set up leads to

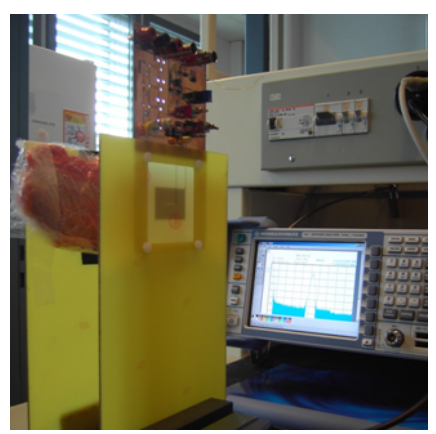

Fig. 4. Measurements are performed with a slice of beef sirloin between the inductors to investigate the behavior of the system in presence of biological tissues.

TABLE I

POWER CONSUMPTION OF THE PATCH IN DIFFERENT OPERATING MODES.

\begin{tabular}{|c|c|c|c|c||c|}
\cline { 2 - 6 } \multicolumn{1}{c|}{} & Bluetooth Module & Voltage Monitor & Waveform Gen. & Power Amplifier & Total Power \\
\hline Stand-by Mode & $59.2 \mathrm{~mW}$ & $14.8 \mathrm{~mW}$ & - & - & $74 \mathrm{~mW}$ \\
\hline Connection Mode & $185 \mathrm{~mW}$ & $14.8 \mathrm{~mW}$ & - & - & $199.8 \mathrm{~mW}$ \\
\hline $\begin{array}{c}\text { Power Mode } \\
\text { (BT Disconnected) }\end{array}$ & $59.2 \mathrm{~mW}$ & $14.8 \mathrm{~mW}$ & $125.8 \mathrm{~mW}$ & $340.4 \mathrm{~mW}$ & $540.2 \mathrm{~mW}$ \\
\hline $\begin{array}{c}\text { Power Mode } \\
\text { (BT Connected ) }\end{array}$ & $185 \mathrm{~mW}$ & $14.8 \mathrm{~mW}$ & $125.8 \mathrm{~mW}$ & $340.4 \mathrm{~mW}$ & $666 \mathrm{~mW}$ \\
\hline
\end{tabular}

an overall efficiency slightly smaller than the theoretical one. With this tuning, the power transmitted to the receiving coil versus the distance between the inductors in ambient air is reported in Fig. 3. At a distance of $6 \mathrm{~mm}$, the received power is about $15 \mathrm{~mW}$. Measurements have been performed by using beef sirloin between the inductors to simulate the presence of biological tissues (Fig 4). With a $17 \mathrm{~mm}$ thick slice of sirloin between the coils, the transferred power is $1.17 \mathrm{~mW}$. This value is comparable with that obtained in ambient air, where the distance between the coils is set to $17 \mathrm{~mm}$ (Fig. 3).

Finally, downlink communication is successfully tested at $100 \mathrm{kbps}$, while uplink communication is successfully tested at $66.6 \mathrm{kbps}$. These values satisfy the design specifications previously introduced.

\section{B. Battery Consumption}

The system can operate in different modes. A summary of the power drawn from the $7.4 \mathrm{~V}$ supply in the different operating modes is reported in Table I.

In stand-by mode, the bluetooth is not connected but intermittently inquires for possible connections. The analog supply AVdd is disconnected and the amplifier is disabled. Digital circuits are disabled and the microcontroller is in low-power mode. The voltage monitor checks the batteries to prevent over-discharge. The total power consumption is about $74 \mathrm{~mW}$, with an estimated battery duration of about $10 \mathrm{~h}(80 \%$ of battery discharge).

In connection mode, the bluetooth module communicates with a remote device. Consequently, the power consumption increases. This additional power is the only difference with the stand-by mode. The total power consumption in connection mode is about $200 \mathrm{~mW}$, with an estimated battery duration of about $3.5 \mathrm{~h}$. 
TABLE II

COMPARISON AMONG INDUCTIVE POWERING SYSTEMS UTILIZED FOR IMPLANTABLE DEVICES.

\begin{tabular}{|c|c|c|c|c|c|c|c|c|c|c|}
\hline Ref. & Coil Area & Coil Thickness & $\begin{array}{c}\text { Carrier } \\
\text { Frequency }\end{array}$ & $\begin{array}{c}\text { Data } \\
\text { Transmission }\end{array}$ & $\begin{array}{c}\text { Transmitted } \\
\text { Power }\end{array}$ & $\begin{array}{c}\text { Link } \\
\text { Efficiency }\end{array}$ & Distance & FOM $\mathbf{3 D}-\eta$ & FOM \\
\hline 3D $-\mathbf{P}$ & $\begin{array}{c}\text { Transmitter } \\
\text { Wearability }\end{array}$ \\
\hline$[10]$ & $\begin{array}{c}\text { Tx: } 1960 \mathrm{~mm}^{2} \\
\text { Rx: } 314 \mathrm{~mm}^{2}\end{array}$ & $\begin{array}{c}\text { Tx: } 9.5 \mathrm{~mm} \\
\text { Rx: } 5 \mathrm{~mm}\end{array}$ & $4 \mathrm{MHz}$ & Uplink & $11 \mathrm{~mW}$ & - & $28 \mathrm{~mm}$ & - \\
\hline$[11]$ & $\begin{array}{c}\text { Tx: } 1.32 \cdot 10^{5} \mathrm{~mm}^{2} \\
\text { Rx: } 79 \mathrm{~mm}^{2}\end{array}$ & $\begin{array}{c}\text { Tx: } 300 \mathrm{~mm} \\
\text { Rx: } 13 \mathrm{~mm}\end{array}$ & $1 \mathrm{MHz}$ & - & $150 \mathrm{~mW}$ & $1 \%(\mathrm{~min})$. & $205 \mathrm{~mm}$ & $-26.62 \mathrm{~dB}$ & $-14.86 \mathrm{dBW}$ & $\begin{array}{c}\text { Surrounding } \\
\text { the body }\end{array}$ \\
\hline$[12]$ & $\begin{array}{c}\text { Tx: } 1963 \mathrm{~mm}^{2} \\
\text { Rx: } 35 \mathrm{~mm}^{2}\end{array}$ & $\begin{array}{c}\text { Tx: } 5 \mathrm{~mm} \\
\text { Rx: } 1.9 \mathrm{~mm}\end{array}$ & $5 \mathrm{MHz}$ & Downlink & $10 \mathrm{~mW}$ & - & $40 \mathrm{~mm}$ & - \\
\hline$[13]$ & $\begin{array}{c}\text { Tx: } 400 \mathrm{~mm}^{2} \\
\text { Rx: } 4 \mathrm{~mm}^{2}\end{array}$ & $\begin{array}{c}\text { Tx: } 3.8 \cdot 10^{-2} \mathrm{~mm} \\
\text { Rx: } 3.8 \cdot 10^{-2} \mathrm{~mm}\end{array}$ & $915 \mathrm{MHz}$ & - & $0.14 \mathrm{~mW}$ & $0.06 \%(\max )$. & $15 \mathrm{~mm}$ & $-8.80 \mathrm{~dB}$ & $-15.12 \mathrm{dBW}$ & - \\
\hline $\begin{array}{c}\text { Present } \\
\text { work }\end{array}$ & $\begin{array}{c}\text { Tx: } 912 \mathrm{~mm}^{2} \\
\text { Rx: } 76 \mathrm{~mm}^{2}\end{array}$ & $\begin{array}{c}\text { Tx: } 3.8 \cdot 10^{-2} \mathrm{~mm} \\
\text { Rx: } 0.544 \mathrm{~mm}\end{array}$ & $5 \mathrm{MHz}$ & Bidirectional & $15 \mathrm{~mW}$ & $4.41 \%(\max )$ & $6 \mathrm{~mm}$ & $-9.02 \mathrm{~dB}$ & $-13.70 \mathrm{dBW}$ & $\begin{array}{c}\text { Skin } \\
\text { Patch }\end{array}$ \\
\hline
\end{tabular}

In power mode, the analog and digital circuits are enabled and the amplifier is operative. The system transmits power or communicates with the implanted device. It is possible to further split up this operating mode in two cases, according to the bluetooth status (connected or not). With the chosen tuning, the amplifier consumes about $340 \mathrm{~mW}$. When the bluetooth is not connected, the measured battery duration in power mode is about $1.5 \mathrm{~h}$.

\section{Comparison with the Literature}

The system has been compared with other energy harvesting systems presented in literature [10-13]. The $\mathrm{FOM}_{3 \mathrm{D}-\eta}$ and the $\mathrm{FOM}_{3 \mathrm{D}-\mathrm{P}}$ are used as figures of merit. The $\mathrm{FOM}_{3 \mathrm{D}-\eta}$ is defined as follows

$$
\mathrm{FOM}_{3 \mathrm{D}-\eta}=10 \log \left[\frac{d^{3}}{V_{1}+V_{2}} \times \eta\right],
$$

where $d$ is the distance between the inductors, $V_{1}$ and $V_{2}$ are the volumes of the external and internal inductors, and $\eta$ is the link efficiency. The delivered power $P$ is considered in the $\mathrm{FOM}_{3 \mathrm{D}-\mathrm{P}}$

$$
\mathrm{FOM}_{3 \mathrm{D}-\mathrm{P}}=10 \log \left[\frac{d^{3}}{V_{1}+V_{2}} \times \mathrm{P}\right] .
$$

The comparison between the proposed system and other similar designs is listed in Table II. The link efficiency of the system also includes the losses due to the amplifier; consequently, a smaller efficiency is reported as compared to Section 3.

The system exhibits a comparable performance with the other devices. However, while the other systems are focused on the receiver, the device proposed aims to the wearability of the external transmitter. Indeed, the patch is easily wearable and completely autonomous in terms of supply. Finally, it can be remotely controlled by using bluetooth connection.

\section{CONCLUSIONS}

A wearable system to power implanted sensors by means of an inductive link is presented. The system has size $69 \times 40 \mathrm{~mm}^{2}$ and is designed to be embedded into a skin patch and placed directly over the implantation area. The device supports power transmission and bidirectional data communication with implanted sensors. It can transfer up to $15 \mathrm{~mW}$ within $6 \mathrm{~mm}$ in air when an 8-layers, 14-turns planar inductor is used as receiver. Tested with a $17 \mathrm{~mm}$ thick beef sirloin between the inductors, the system can transfer up to $1.17 \mathrm{~mW}$. Downlink communication is performed at $100 \mathrm{kbps}$ by means of ASK modulation. Uplink communication is performed at $66.6 \mathrm{kbps}$ by means of load modulation. Long range communication between the system and remote devices is enabled by an embedded bluetooth module. The patch is powered by two thin LiPo batteries and has an autonomy of about $10 \mathrm{~h}$ in stand-by mode and about $1.5 \mathrm{~h}$ in power mode.

Finally, while presenting a performance comparable to similar devices, listed in Table II, the patch offers a high wearability, a good autonomy in terms of power supply, and the possibility to be remotely controlled by using bluetooth communication.

\section{REFERENCES}

[1] M. Frost and M. Meyerhoff, "Implantable Chemical Sensors for Realtime Clinical Monitoring: Progress and Challenges," Curr. Opin. Chem. Biol., vol. 6, no. 5, pp. 633 - 641, Oct. 2002.

[2] P. Mitcheson, E. Yeatman, G. Rao, A. Holmes, and T. Green, "Energy Harvesting from Human and Machine Motion for Wireless Electronic Devices," Proc. IEEE, vol. 96, no. 9, pp. 1457-1486, Sept. 2008.

[3] J. Olivo, S. Carrara, and G. De Micheli, "Energy Harvesting and Remote Powering for Implantable Biosensors," IEEE Sens. J., vol. 11, no. 7, pp. 1573-1586, Jul. 2010.

[4] D. Gough, L. Kumosa, T. Routh, J. Lin, and J. Lucisano, "Function of an Implanted Tissue Glucose Sensor for More Than 1 Year in Animals," Sci. Transl. Med., vol. 2, pp. 42-53, 2010.

[5] M. Ahmadi and G. Jullien, "A Wireless-implantable Microsystem for Continuous Blood Glucose Monitoring," IEEE Trans. Biomed. Circuits Syst., vol. 3, no. 3, pp. $169-180$, Jun. 2009.

[6] B. Lenaerts and R. Puers, Omnidirectional Inductive Powering for Biomedical Implants. Springer, 2009.

[7] N. Sokal, "Class-E RF Power Amplifiers," $Q E X$, pp. 9-20, Jan./Feb. 2001.

[8] F. Raab, "Idealized Operation of the Class-E Tuned Power Amplifier," IEEE T. Circuits. Syst., vol. CAS-24, no. 12, pp. 725-735, Dec. 1977.

[9] J. Olivo, S. Carrara, and G. De Micheli, "Optimal Frequencies for Inductive Powering of Fully Implantable Biosensors for Chronic and Elderly Patients," in Proc. IEEE Sensors Conf., 2010, pp. 99-103.

[10] C. Sauer, M. Stanaćević, G. Cauwenberghs, and N. Thakor, "Power Harvesting and Telemetry in CMOS for Implanted Devices," IEEE T. Circuits-I., vol. 52, no. 12, pp. 2605 - 2613, Dec. 2005.

[11] B. Lenaerts and R. Puers, "An Inductive Power Link for a Wireless Endoscope," Biosens Bioelectron, vol. 22, no. 7, pp. 1390 - 1395, Feb. 2007.

[12] G. Gudnason, E. Bruun, and M. Haugland, "A Chip for an Implantable Neural Stimulator," Analog Integr. Circuits Signal Process., vol. 22, no. 1, pp. 81-89, Jan. 2000.

[13] S. O'Driscoll, A. Poon, and T. Meng, "A mm-sized Implantable Power Receiver with Adaptative Link Compensation," in IEEE ISSCC - Digest of Technical Papers, 2009, pp. 294-295, 295a. 